\title{
The Effect of Slot Sizes on Non-Asymmetry Slot Antenna for Microwave Coagulation Therapy
}

\author{
Wannaree Wongtrairat, Pattarapong Phasukkit, Supan Tungjitkusolmun, and Petch Nantivatana
}

\begin{abstract}
This paper presents analyses of non-asymmetry antenna configuration for microwave ablation at $2450 \mathrm{MHz}$ using three-dimensional finite element analyses. Treatment of hepatic cancer often requires removal or destruction. Using coaxial-slot antenna is opened slot at one-side of antenna. We study the characteristics of various slot size and various power for non-asymmetry structure antenna to observe temperature distributions and SAR. The results illustrate that the coaxial-slot non-asymmetry structure antenna can be used in microwave ablation for destruction of the cancer cell in the area closed to the very fragile tissue or blood vessel.
\end{abstract}

Index Terms-Microwave(MW) ablation, finite-element(FE) analysis, non-asymmetry structure antenna.

\section{INTRODUCTION}

In hyperthermic oncology, cancer is treated by applying localized heating to the tumor tissue, often in combination with chemotherapy or radiotherapy. Some of the challenges associated with the selective heating of deep-seated tumors without damaging surrounding tissue are, control of heating power and spatial distribution and design and placement of temperature sensors. Among possible heating techniques, RF and microwave heating have attracted much attention from clinical researchers. Microwave coagulation therapy is one such techniques where a thin microwave antenna is inserted into the tumor. The microwave heats up the tumor, producing a coagulation region where temperature above $50^{\circ} \mathrm{C}$ is reached and the cancer cells are effectively destroyed.

In recent years, various types of medical applications of microwaves have been widely investigated. L. Hamada et al. [1] performed an experiment using dipole antenna at 915 $\mathrm{MHz}$, with varying insertion depths, and compared the results with conventional antenna. In 1996, [2] presented new dipole antenna called "Cap-choke antenna" which was used in an experiment at a frequency of $2.45 \mathrm{GHz}$ [3] and $915 \mathrm{GHz}$ [4]. Hurter et al [5] used computer simulation [6] to investigate a new antenna design called "tri-axial chocked dipole antenna"

Manuscript received July 15, 2011; revised August 30, 2011.

W. Wongtrairat is with Department of Electronics Engineering, Faculty of Engineering and Architecture, Rajamangala University of Technology Isan, Nakhonratchasima 30000, Thailand (e-mail: wannaree.wo@rmuti.ac.th).

P. Phasukkit is with Department of Electronics Engineering, Faculty of Engineering, King Mongkut's Institute of Technology Ladkrabang, Bangkok 10520, Thailand (corresponding author to provide e-mail: kppattar@kmitl.ac.th).

S. Tungjitkusolmun is with Department of Electronics Engineering, Faculty of Engineering, King Mongkut's Institute of Technology Ladkrabang, Bangkok 10520, Thailand (e-mail: ktsupan@kmitl.ac.th).

P. Nantivatana is with Department of Electronics Engineering, Faculty of Engineering, King Mongkut's Institute of Technology Ladkrabang, Bangkok 10520, Thailand (e-mail: petch.na@spu.ac.th). and discovered that it has higher SAR values than dipole antenna and helps reduce the effect of insertion depth. Saito et al [7],[8] used two coaxial-fed slot coaxial antenna for microwave ablation at $2.45 \mathrm{GHz}$ which resulted in larger lesion sizes than using one coaxial antenna.

Microwave (MW) ablation method is another alternative for curing cancer and is emerging as a new treatment option for patients with unrespectable hepatic malignancies [9],[10]. Similar to RF ablation, MW current is passed to cancer tissues typically via an antenna which causes generation of Joule Heat to selective targeted areas. However, the zone of active tissue heating from RF probe is limited to a few millimeters surrounding the active electrode, with the remainder of the ablation zone being heated via thermal conduction [11]. Owing to the much broader field of power density of the electromagnetic field in MW ablation (up to $2 \mathrm{~cm}$ surrounding the antenna [11], [7]), MW ablation results in a much larger zone of active heating than RF ablation. In addition, manipulating the designs of MW antenna has a greater effect on electromagnetic field distributions which in turn govern the temperature distributions found in unwanted tissue. RF ablation is also limited by the increase in impedance with tissue boiling and charring because water vapor and char act as electric insulators. Due to the electromagnetic nature of MW, ablations performed do not seem to be subjected to this limitation, thus allowing the intramural temperature to be driven considerably higher, resulting in a larger ablation zone within a shorter ablation duration [11], [7]. Thus, MW ablation offers many of the benefits of RF ablation but has several theoretical advantages that may result in larger lesion formation, and improved performance near blood vessels [11].

Several studies on MW ablation have been previously reported over the past decade. In 1996, Labonté et al. [12] introduced three types of MW antennas—open-tip monopole (OTM), dielectric-tip monopole (DTM), and metal-tip monopole (MTM)—operating at $2.45 \mathrm{GHz}$ for cardiac ablation. They compared the three antenna designs using finite element (FE) analysis and found that MTM provided the smoothest temperature distribution in surrounding tissue. MTM was also found to be well matched at low frequencies but has a high $\mathrm{S}_{11}$ of $-5 \mathrm{~dB}$ at $2.45 \mathrm{GHz}$. OTM exhibited the lowest $\mathrm{S}_{11}$ (good matching impedance) at $2.45 \mathrm{GHz}$ and its temperature distribution was found to be relatively smooth.

The clinically used MW devices show varying sizes of coagulation volume depending on their geometry: applicators of straight geometry are reported to achieve coagulation diameters of up to $2.5 \mathrm{~cm}$ [13], whereas single loop-antenna applicators were reported to result in coagulation diameters of up to $3.5 \mathrm{~cm}[14]$. Other notable proposed MW antenna designs include: cap-choke catheter antenna proposed by Lin 
et al. [15] for MW treatment with localized heating of tissue surrounding the distal end of the catheter, the floating sleeve antenna proposed by Yang et al. [16] where the inclusion of the floating sleeve could prevent the flow of electromagnetic energy along the coaxial applicator.

Numerical simulation has been used extensively in studies of RF \& MW ablation as it offers a fast and economical way to evaluate new hypothetical designs. Simulations of three-dimensional (3-D) coupled thermal-electric FE analysis were previously introduced for RF ablation [17]-[22]. However all previous FE analysis for MW hepatic ablation have been performed in two dimensions (approximating the geometry of the FE model to be asymmetric) [2], [23]-[30]. Lui et al.[31] studied thermal characteristics of MW Ablation in the vicinity of arterial bifurcation using 3-D thermal FE model. In this paper, we investigated coaxial-slot non-asymmetry structure antenna by varying the slots size and varying power. We perform the analyses using $3 \mathrm{D}$ finite element modeling. same as [32]. For comparison of the results, we determine the SAR and temperature distributions in tissue generated by the antennas with different slot size.

\section{STRUCTURE OF NON-SYMMETRY ANTENNA}

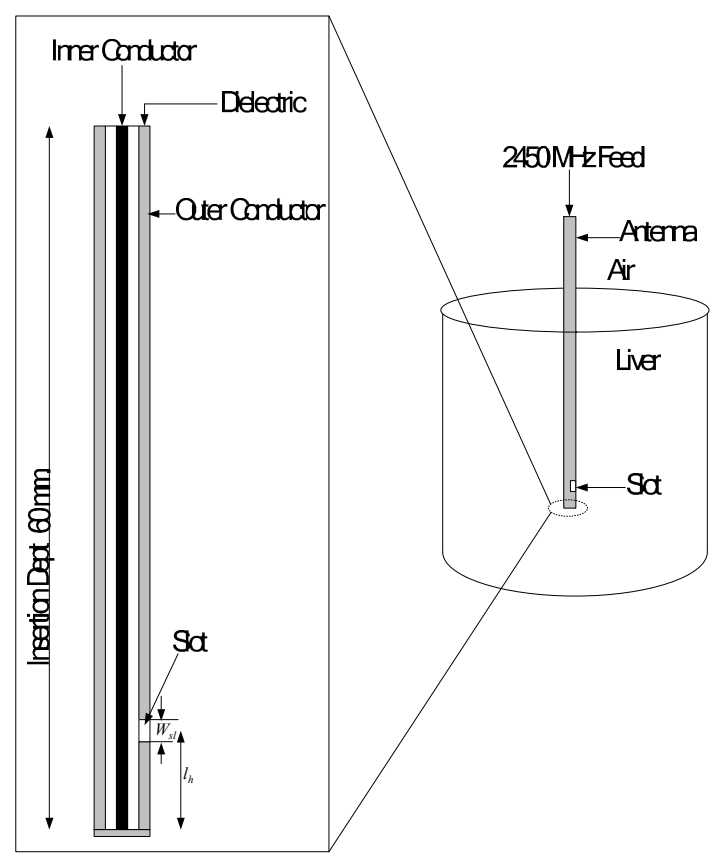

Fig. 1. Antenna Structure.

Fig. 1 and Table 1 we show the configuration and parameters of coaxial-slot non-asymmetry structure antenna used in this study. This structure is the same as [7], [8].

\section{A. Antenna Designs}

The antennas used in experiment were semi-rigid coaxial cable (RG 402 M17/130-RG402 Copper Jacket, EMC Technology and Florida RF Labs, Stuart, FL) having a diameter of $3.51 \mathrm{~mm}$, and were used N-type connector. We modified this semi-rigid coaxial antenna to obtain different length of slot open (one side) dimensions of the antenna, which are the specified as shown in TABLE 1.
TABLE 1:DIMENSIONS OF THE ANTENNA.

\begin{tabular}{c|c}
\hline Inner conductor [mm.] & 1.02 \\
Diameter of dielectric [mm.] & 3.02 \\
Diameter of outer conductor [mm.] & 3.53 \\
Length from the tip to the center of the slot [mm.] & 20 \\
Insertion depth [mm.] & 50 \\
Length of antenna [mm.] & 60 \\
Width of the slot [mm.] & 2 \\
Length of slot [mm.] & $2,4,6,8$ \\
\hline
\end{tabular}

\section{B. Properties of Antennas}

The graphical illustration in Fig. 2 shows the antenna characteristics measured from Bird Site Analyzer Model SA-600 EX (Bird Electronic Corporation, Cleveland, OH). We measured the Return Loss values of the antennas in the range of 2.3-2.7 GHz that covered our operating frequency of $2.45 \mathrm{GHz}$. All measurements were performed by inserting each antenna in a $10 \mathrm{~cm} \times 10 \mathrm{~cm}$ freshly excised swine liver obtained from a local slaughterhouse. From the results in Fig. 2, all antenna design have low Return Loss(-16.8 dB, -17.8 $\mathrm{dB},-18.5 \mathrm{~dB}$ and $-19.7 \mathrm{~dB}$ for slot length $2 \mathrm{~mm}$., $4 \mathrm{~mm}$., 6 $\mathrm{mm}$. and $8 \mathrm{~mm}$, respectively). Antennas with low Return Loss are desirable because they can drive more energy into tissue. From Fig. 2, when increasing slot length the Return Loss value will decrease, that mean more energy transfer into tissue. Thus we can improve antenna characteristics by change the length of slot side.

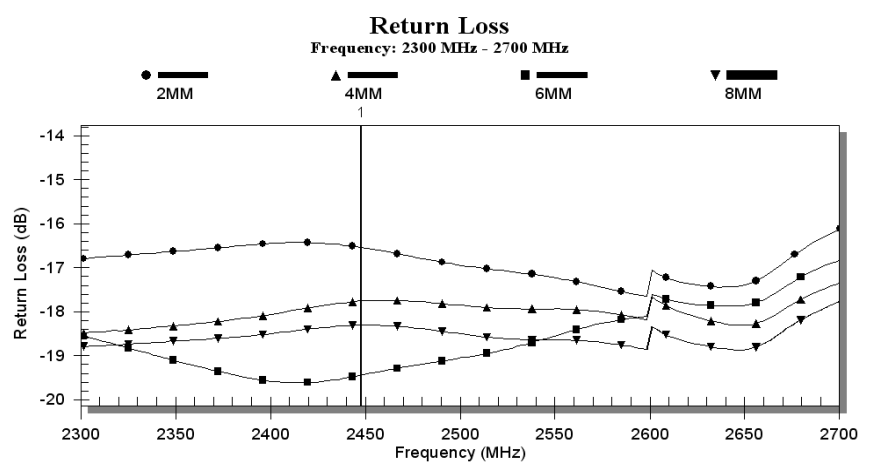

Fig. 2. Antenna characteristics (Return loss) of open-slot one side antennas at slot length $2 \mathrm{~mm}, 4 \mathrm{~mm}, 6 \mathrm{~mm}$ and $8 \mathrm{~mm}$, over frequency range 2300-2700 $\mathrm{MHz}$ obtained from the Bird Site Analyzer Model SA-6000 Ex.

\section{Finite ELEMENT ANALYSIS}

The finite element method (FEM) involves dividing a complex geometry into small elements for a system of partial differential equation, evaluated at nodes or edges.

\section{A. Bioheat Equation}

The source of heat transfer in MW ablation is from electromagnetic wave at $2.45 \mathrm{GHz}$ transmitted into tissues. Joule heating arises when energy dissipated by an electric current flowing through a conductor is converted into thermal energy. Tissue temperature changes over time can be predicted by the bio-heat equation [33]:

$\rho C \frac{\partial T}{\partial t}+\nabla \cdot(-k \nabla T)=\rho_{b} C_{b} \omega_{b}\left(T_{b}-T\right)+Q_{m e t}+Q_{e x t}$,

where

$$
\begin{aligned}
& \rho=\text { Density }\left[\mathrm{kg} / \mathrm{m}^{3}\right] \\
& C=\text { Specific heat }[\mathrm{J} / \mathrm{kg} \cdot \mathrm{K}]
\end{aligned}
$$




$$
\begin{aligned}
k= & \text { Thermal conductivity }[\mathrm{W} / \mathrm{m} \cdot \mathrm{K}] \\
J= & \text { Current density }\left[\mathrm{A} / \mathrm{m}^{2}\right] \\
E= & \text { Electric field intensity }[\mathrm{V} / \mathrm{m}] \\
T_{b 1}= & \text { Temperature of the blood }\left[{ }^{\circ} \mathrm{C}\right] \\
\rho_{b 1}= & \text { The blood density }\left[\mathrm{kg} / \mathrm{m}^{3}\right] \\
C_{b 1}= & \text { Specific heat of the blood }[\mathrm{J} / \mathrm{kg} \cdot \mathrm{K}] \\
\omega_{b 1}= & \text { blood perfusion }[1 / \mathrm{s}] \\
h_{b 1}= & \text { The convective heat transfer coefficient } \\
& \text { accounting for blood perfusion in the } \\
& \text { model } \\
Q_{\text {met }}= & \text { The energy generated by the metabolic } \\
& \text { processes }\left[\mathrm{W} / \mathrm{m}^{3}\right] .
\end{aligned}
$$

Since $Q_{\text {met }}$ is negligible, we excluded it from our FE models. We also omitted $h_{b 1}$ from our preliminary studies.

\section{B. SAR Distribution}

In order to evaluate the heating ability of the antenna, SAR distribution is widely used. The SAR shows the heat generated by the electric field in the tissue given by

$$
S A R=\frac{\sigma}{\rho} E^{2} ; \quad[W / k g]
$$

where

$$
\begin{aligned}
\sigma & =\text { conductivity of tissue }[\mathrm{S} / \mathrm{m}] \\
\rho & =\text { Density of tissue }\left[\mathrm{kg} / \mathrm{m}^{3}\right] \\
E & =\text { Electric field }[\mathrm{V} / \mathrm{m}] .
\end{aligned}
$$

In this study, we calculate SAR distributions for all cases and compare the results to determine the potential heating patterns of the antennas. The thermal and electrical properties used are from [9]. We can link the volume of SAR to this following heat equation (3) below

$$
\rho C \frac{\partial T}{\partial t}+\nabla \cdot(-k \nabla T)=\rho_{b} C_{b} \omega_{b}\left(T_{b}-T\right)+\rho \cdot S A R .
$$

\section{Simulation}

In this paper, we performed computer simulation using the finite element method. We selected COMSOL 3.5a (Comsol Inc., Burlington, MA), to solve our thermal-electrical problems. In process of Finite element method, we used a non-uniform mesh and a three dimension model in this study on the 64 bit Sun Fire 240 operating system ( 2 processor with Ram 8 GB). The simulation consists of 2 modules:

1) RF Module.

2) Heat Transfer (Bioheat Equation).

We creates the antenna and other components by Solid Work version 2009 emitting in the form of IGS to COMSOL Multi-physic Version 3.5a in order that the boundary is put together with other invariants used for simulating the work by requiring that record shall be made every second for 300 seconds. The detail of the simulation parameter is as follows:

Parameter for simulating

$$
\begin{array}{ll}
\text { the density of tissue } & =1050 \mathrm{~kg} / \mathrm{m}^{3}, \\
\text { specific heat of Liver } & =3700 \mathrm{~J} / \mathrm{kgK}, \\
\text { density of blood } & =1000 \mathrm{~kg} / \mathrm{m}^{3}, \\
\text { specific heat of blood } & =3639 \mathrm{~J} / \mathrm{kgK}, \\
\text { blood perfusion rate } & =3.6 \times 10^{-3} \mathrm{~m}^{3} / \mathrm{kg} \cdot \mathrm{s}, \\
\text { thermal conductivity of liver } & =0.56 \mathrm{~S} / \mathrm{m}, \\
\text { parameter of electrical properties, } \varepsilon_{\text {liver }} & =43.03, \\
\text { (Relative permittivity) } & =1.69 \mathrm{~S} / \mathrm{m}, \\
\text { Electrical Conductivity, } \delta_{\text {liver }} & =2.03, \\
\varepsilon_{\text {dielectric }} & =2.6 .
\end{array}
$$

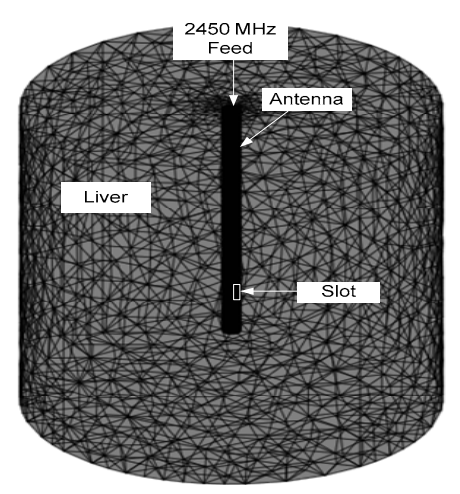

Fig. 3. FEM Model.

Fig. 3 shows triangular element with irregular tetrahedral. The number of elements used for simulation is 131,765 approximately, the number of degree of freedom is 947,089 and memory for running is 1,262 MByte approximately.

In Fig 4, the distance from the antenna is $5 \mathrm{~mm}$. The $\mathrm{Ob}$ servation Line 1 on the side of slot opening. On the side opposite to the slot opening, the distance of the observation line is $5 \mathrm{~mm}$. to observe the SAR volume and the temperature at each level. The Observation Line 1 shows the change of the temperature at the slot opening.

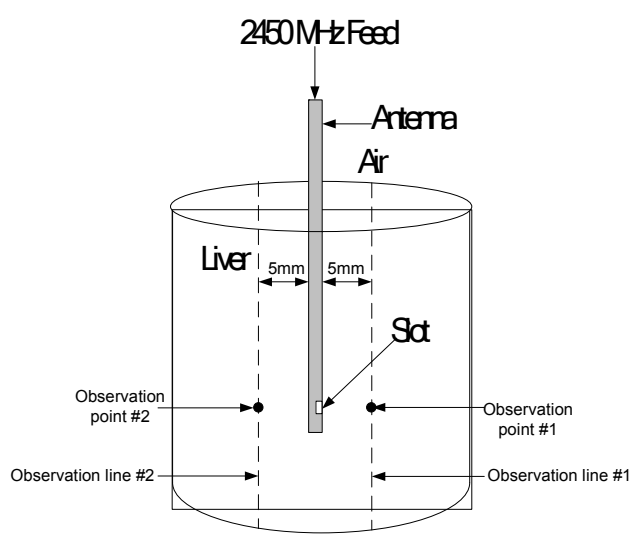

Fig. 4. Observation line at $5 \mathrm{~mm}$. and Observation point.

\section{RESULT}

The result of the simulation in this article shows the result of the simulation by the 3 dimension finite element.

Fig. 5 and Fig. 6 show the distribution of SAR at the liver tissue. Fig. 5 shows that SAR highly distributes in the liver tissue. At the slot, in Fig. 6, the graph shows the volume of SAR in each level. The volume of SAR in the vertical line is the normalized volume of SAR and the horizontal line shows 
the depth in meter. The graph is to compare the volume of SAR of the antenna with different length of slots. It is found that the longer the slot of the antenna is higher the SAR level at $0.03-0.04$ meter which is the same level as the slot, the $\mathrm{SAR}$ is found in the maximum level. This means the maximum level of the magnetic field.

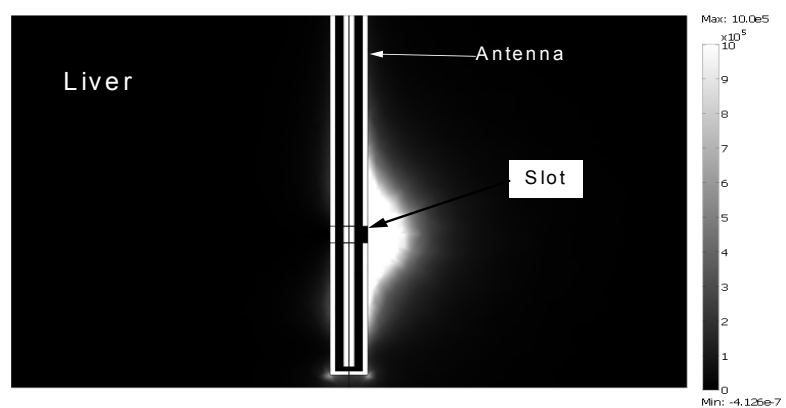

Fig. 5. SAR distribution of antenna.

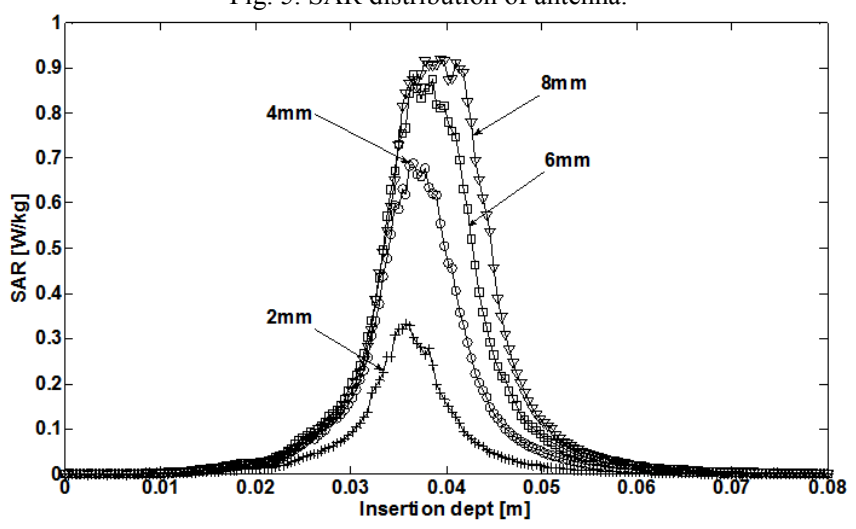

Fig. 6. A graph shows distribution of SAR from the Observation Line No. 1 with distance $5 \mathrm{~mm}$. from the antenna.

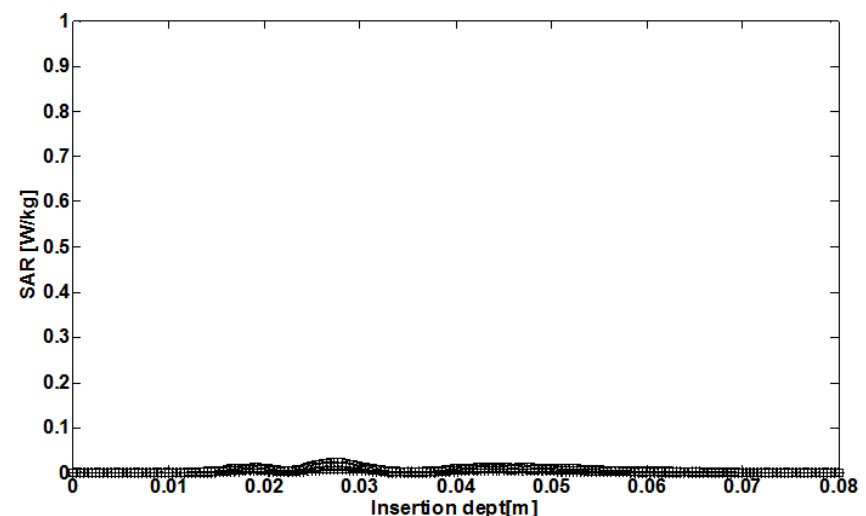

Fig. 7. A graph showing distribution of SAR from the Observation Line No. 2 with distance $5 \mathrm{~mm}$. from the antenna.

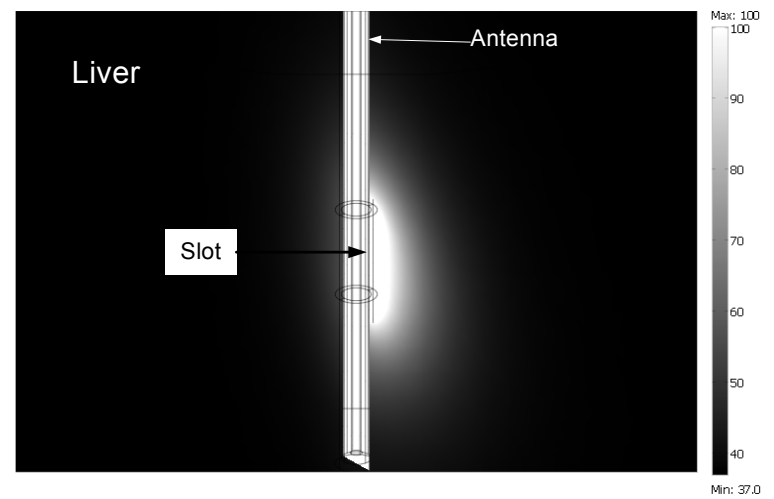

Fig. 8. Distribution of temperature at the liver tissue.
Fig. 7 shows the volume of SAR. At various levels of the Observation Line No. 2 at the opposite side to the slot opening, it is found that the level of the SAR is very low both at the antenna with both large and short slot.

Fig. 8 and the graph in Fig. 9 show the temperature at various levels of the tissue. The Fig. 8 shows that the temperature at the slot is higher than at other areas. Fig. 9 shows the temperature at various levels of depth. The temperature at the depth of $0.03-0.04$ meter is higher than at other levels of depth of the antenna since it is the level of the antenna slot and the longer slot will cause higher temperature.

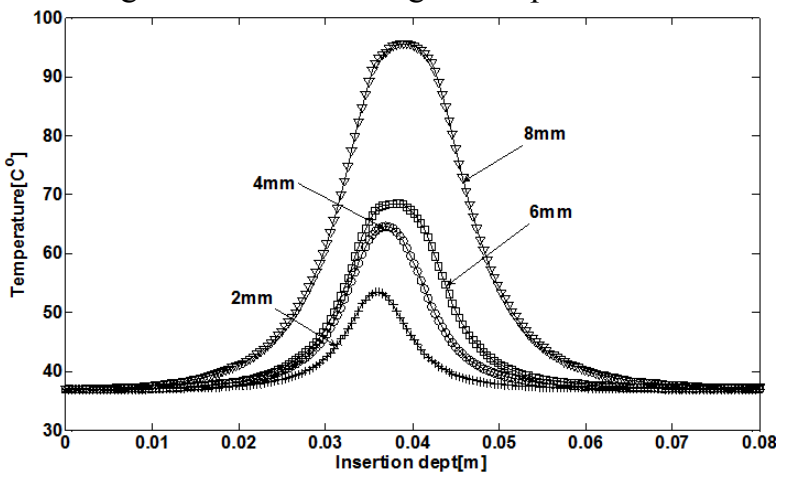

Fig. 9. A graph showing the distribution of the temperature at the liver tissue with various levels of depth of the Observation Line No. 1 at the distance of 5 $\mathrm{mm}$. from the antenna.

The Fig. 10 shows the temperature at various depths. At the Observation Line No. 2 at the opposite side of the slot opening, the temperature is very low, whereas the temperature at the depth of the slot is slightly higher than at other levels. The difference between the antenna with the largest slot and that with the smallest slot is $4^{\circ} \mathrm{C}$, which is very low.

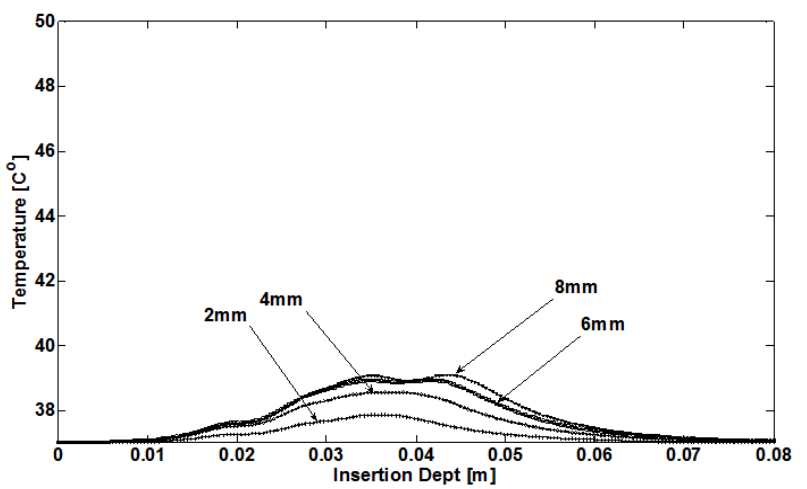

Fig. 10. A graph showing the distribution of the temperature at the liver tissue with various levels of depth of the Observation Line No. 2 at the distance of $5 \mathrm{~mm}$. from the antenna.

Fig. 11 shows the temperature change during $0-300$ seconds at the Observation Point No. 1 at the same level as the slot opening. The dark line shows results from the simulation and the dashed line shows results from the experiment. This was measured by the temperature sensor at the distance $5 \mathrm{~mm}$. far from the antenna. The details are shown at the Fig. 4.

The results of the temperature change of the antennas with different length of the slot, according to the experiment, is that the temperature at the beginning is lower since during the setup we set $30^{\circ} \mathrm{C}$ at the liver. The result from the experiment is $6 \%$ lower than the result from the actual operation. The temperature of the antenna with larger slot is higher than that with smaller slot. 


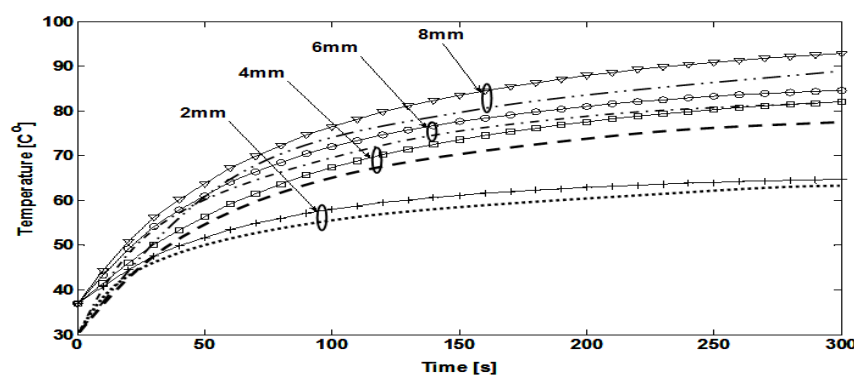

Fig. 11. A graph showing the change of the temperature at $5 \mathrm{~mm}$. distance from the slot at the Observation Point No. 1 during $0-300$ seconds.

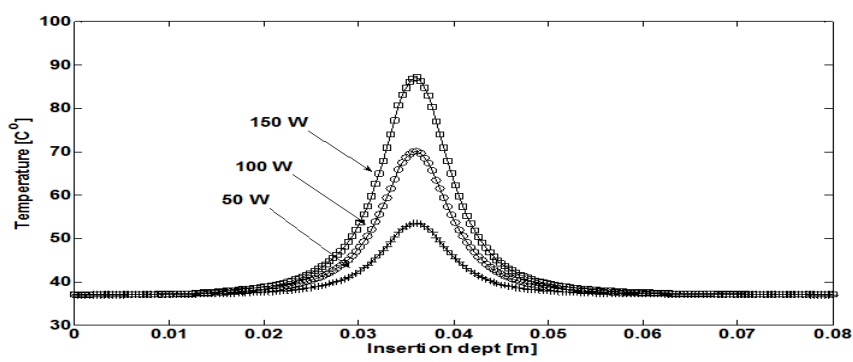

Fig. 12. A graph showing the change in the temperature at the 50,100, 150 watts of antenna with $2 \mathrm{~mm}$. slot at the Observation Line No. 1.

Fig. 12 shows the temperature of the antenna with $2 \mathrm{~mm}$. slot which results in the change of the power supplied to the antenna. The temperature measured at the various levels of depth in various areas including the side to the slot opening (Observation Line No. 1) is very high. When being supplied more power, the temperature is rather slightly changed. The area with the highest temperature is the slot at the depth of $0.03-0.04$ meter.

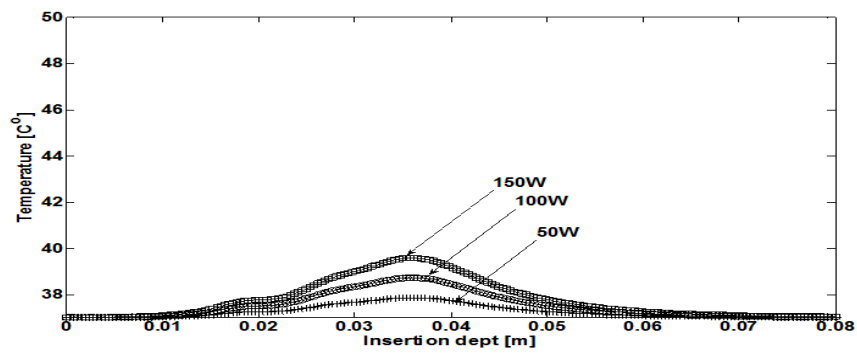

Fig. 13. A graph showing the temperature change at 50, 100, 150 watts of the antenna with $2 \mathrm{~mm}$. slot at the Observation Line No. 2.

Fig. 13 shows the temperature of the antenna with $2 \mathrm{~mm}$. slot which results in the change of the power supplied to the antenna. The temperature measured at the various levels of depth in various areas including the opposite side to the slot opening (Observation Line No. 2) is very low. When being supplied more power, the temperature is rather slightly changed. The area with the highest temperature is the slot at the depth of $0.03-0.04$ meter.

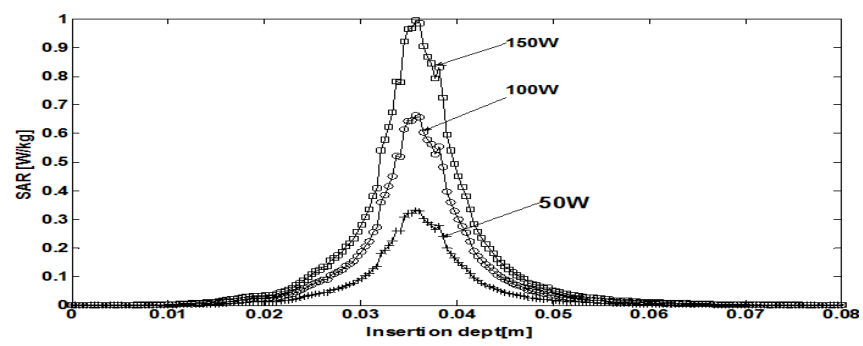

Fig. 14. A graph showing changes in the SAR at the 50,100,150 watts of the antenna with $2 \mathrm{~mm}$. slot at the Observation Line No. 1.

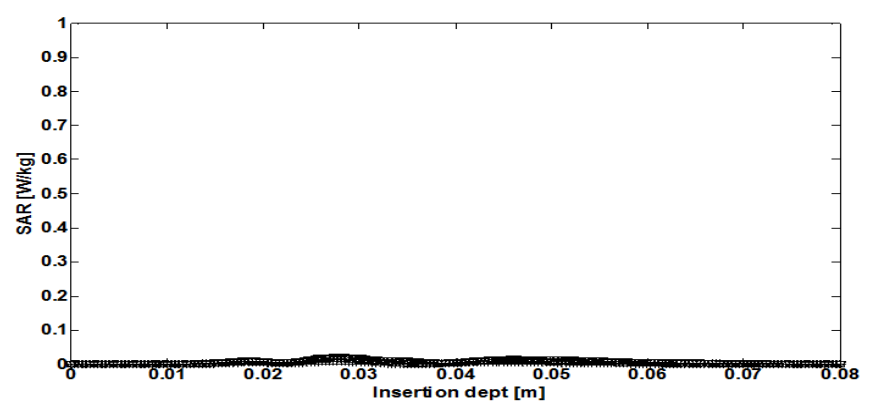

Fig. 15. A graph showing changes in the SAR at the 50,100, 150 watts of the antenna with $2 \mathrm{~mm}$. slot at the Observation Line No. 2.

Graphs at Fig. 14 and Fig. 15 show the SAR at various levels of the depth in the tissue. Fig. 14 shows the SAR at the depth levels in the Observation Line No. 1, at the slot opening. The SAR increases when being supplied with more power to the antenna. The point with the highest level of the SAR is at $0.03-0.04$ meter deep which is the position of the slot. Fig. 15 shows the level of the SAR at various levels of the depth at the Observation Line No. 2, opposite to the slot opening. It is found that the SAR level is very low, even though the power is increased. The SAR level at the opposite side to the slot opening is very low.

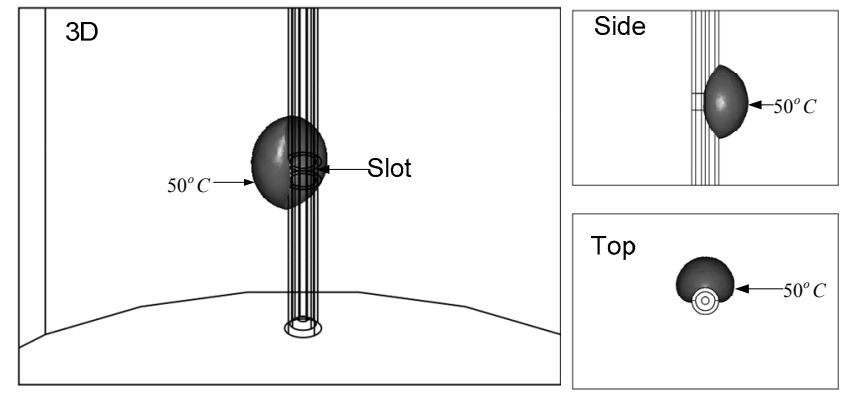

Fig. 16. The 3D temperature distribution in liver tissue.

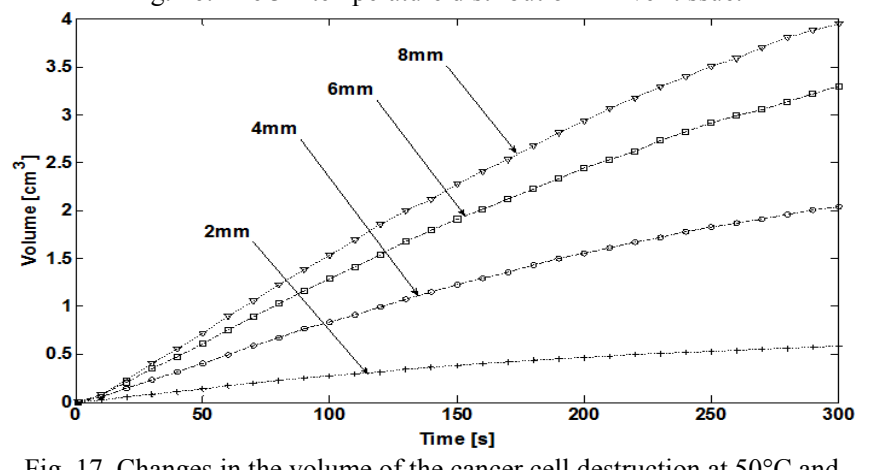

Fig. 17. Changes in the volume of the cancer cell destruction at $50^{\circ} \mathrm{C}$ and over.

This Fig. 16 shows 3-dimension image of the cancer cell destruction at $50^{\circ} \mathrm{C}$ and over. The destruction starts at this level of the temperature. A 50-watt power is supplied to the slot coaxial non-asymmetry antenna with $2 \mathrm{~mm}$. slot at 60 seconds. The volume is $0.172707 \mathrm{~cm}^{3}$. The simulation time is 946.25 seconds and the used memory unit is $1823 \mathrm{MB}$.

Fig. 17 shows the changes in volume of the cancer cell destruction in the tissue at $50^{\circ} \mathrm{C}$ and over from the beginning to 300 seconds with the record made every 10 second. The graph shows time of the changes in the volume in the horizontal line and the volume $\left(\mathrm{cm}^{3}\right)$ in the vertical line. The 50 watt power is consistently supplied to the antenna with $2 \mathrm{~mm}$., 
$4 \mathrm{~mm} ., 6 \mathrm{~mm}$. and $8 \mathrm{~mm}$. - width slot.

The change in the volume of the antenna with 8 mm. - width slot is higher than that with smaller slot. At the point of 300 seconds, the volume of the antenna with $8 \mathrm{~mm}$ slot is 8 times higher than the antenna with $2 \mathrm{~mm}$. slot. According to the simulation with changes in the slot size, it is found that the antenna with larger coaxial non-asymmetric slot provides with higher volume of destruction at $50^{\circ} \mathrm{C}$ than the antenna with smaller slot.

\section{EXPERIMENTAL RESULT}

Fig. 18 shows a diagram for the experimental setup using one MW source capable of controlling the energy level. The MW source is a magnetron oscillator working at $2450 \mathrm{MHz}$, with maximum $\mathrm{CW}$ output of $250 \mathrm{~W}$. The setup also consisted of three sets of measurement systems (Wideband Power Sensor Model 5012 (350-4000 MHz), Bird Electronic Corporation, Cleveland, $\mathrm{OH}$ ). Each sensor was linked to a PC (Pentium D $2.8 \mathrm{GHz}$, Window XP service Pack 2, 2 GB RAM, 300 GB hard disk) via USB 2.0 cable. We cut swine liver into three pieces in order to aid investigation of coagulation zone formation at different locations of the tissue. Each piece of liver tissue used was shaped as a rectangular prism with dimensions of $100 \mathrm{~mm} \times 100 \mathrm{~mm} \times 20 \mathrm{~mm}$. The antenna was held at a fixed position by placing it through a narrow passage on an acrylic frame.

Similar to FE simulations, we utilized open slot one side designs by varied length of slot-open size $-2 \mathrm{~mm}$., $4 \mathrm{~mm}$., 6 $\mathrm{mm}$. and $8 \mathrm{~mm}$.- - for in vitro experiments. The MW power of 50,100 and $150 \mathrm{~W}$ was applied to the antenna for $60 \mathrm{~s}$. During application of the MW energy, we placed swine liver in a water bath heater with temperature of approximately $37^{\circ} \mathrm{C}$. We also added $\mathrm{NaCl}$ into water to increase the conductivity to a level similar to physiological fluid ( $0.9 \%$ saline).

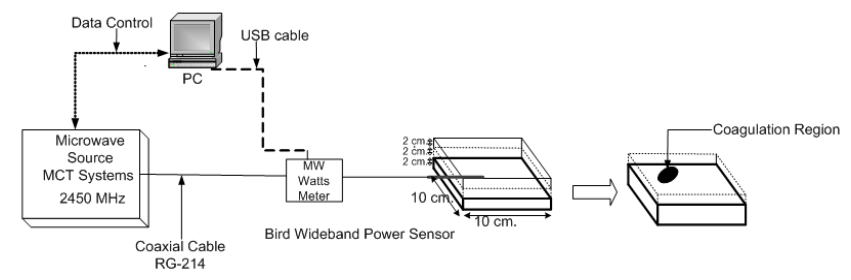

Fig. 18. Diagrams for the experimental setup.

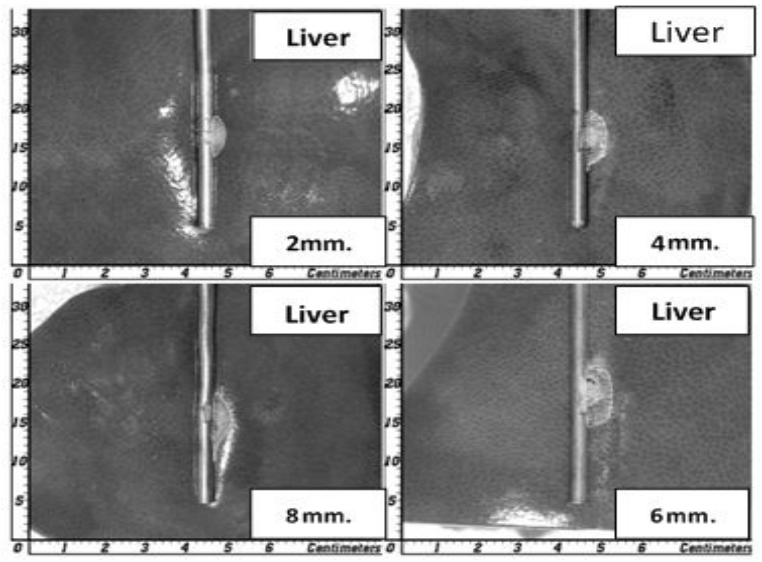

Fig. 19. in Vitro Experiments and Results.

Fig. 19 shows the experiment results. The area of ablation zone related with slot length and ablation zone appear at open slot side only for purpose antenna. The antenna can be radiated microwave energy one side only (open slot) its novel antenna for ablation systems, doctor can be design and apply to some area that crisis.

\section{CONCLUSIONS}

The antennas to be presented are the slot coaxial non-asymmetry whose remarkable characteristic is to cause one-sided heat when the slot is opened. The maximum temperature and the SAR is caused on the one-sided slot. When the length of the slot is changed, the temperature is also changed and the volume of the cancer cell destruction is also higher with no change in power supplied to the antenna. When the power supplied to the antenna is increased, the temperature is also increased. The slot coaxial non-symmetry structure antenna can be used in MCT system which is for destruction of the cancer cell in the area closed to the very fragile tissue.

Major limitations of our experiments are that no blood perfusion or presence of blood vessels were taken into account in our computer models and in vitro experiments. Inclusion of blood perfusion into our models will affect the resulted coagulation zones by reducing the dimensions of coagulation zones are unchanged. Since there is no tissue perfusion in swine liver in in vitro experiments, we exclude parameters for blood perfusion from FE models. Location of the targeted liver tumor in relation to large blood vessels can also change the dimensions, as well as characteristics of resulted coagulation zones [34]. A nonuniform heating MW ablation system might be beneficial to properly ablated both regions close to large blood vessels (more heat) and those that are further away(less heat). In addition, optimal placement configurations by use Non-Asymmetry structure (open-slot one side) multiple antenna for MW ablation needs to be further explored as a recent study by [32].

\section{REFERENCES}

[1] L. Hamada, K Saito, H. Yoshmura, and K. Ito, "Dielectric-Loaded coaxial-slot antenna for interstitial microwave hyperthermia: longitudal, control of heating patterns", Int. J. Hyperthermia, vol. 16, pp. 219-229, 2000.

[2] J. C. Lin and Y. J. Wang, "The cap-choke catheter antenna for mi-crowave ablation treatment", IEEE Trans Biomed Eng., vol. 43, pp. 657-660, 1996.

[3] S. Pisa, M. Cavagnaro, P. Bernardi, and J. C. Lin, “A 915-MHz antenna for microwave thermal ablation treatment: physical design computer modeling and experimental measurement", IEEE Trans Biomed Eng, vol. 48, pp. $599-601,2001$.

[4] W. Hurter, F. Reinbold, and W. J. Lorenz, "A Dippole Antenna for Interstitial Microwave Hyperthermia", IEEE Transactions on Microwave theory and Techniques, vol. 39, pp. 1048-1054, 1991.

[5] G. Schaller, J. Erb, and R. Engelbrecht, "Field Simulation of Dipole Antenna for Interstitial Microwave Hyperthermia", IEEE Trans MTT, vol. 44, pp. 887-895, 1996.

[6] K. Saito, T. Taniguchi, H. Yoshimura, and K. Ito, "Estimation of SAR Distribution of a Tip-Split Array Applicator for Microwave Coagulation Therapy Using the Finite Element Method", IEICE Trans Electron, vol. E84-C, pp. $948-954,2001$.

[7] K. Saito, T. Taniguchi, H. Yoshimura, and K. Ito., "Clinical Trial of Interstitial Microwave Hyperthermia by Use of Coaxial-slot Antenna With Two Slots", IEEE Trans on microwave theory and tech-niques, vol. 52, No. 8, Aug. 2004.

[8] M. Chaichanyut, P. Lertprasert, I. Potejanasaja, and S. Tungjitkusol-mun, "Finite element method for analysis of hepatic cancer tissue de-struction using 2.45 gigahertz antennas", ICBME 2005., Singpapore, Dec. 6-8, 2005. 
[9] M. Lu, J. Chen, X. Xie, L. Liu, X. Huang, L. Liang, and J. Huang, "Hepatocellular carcinoma: US-guided percutaneous microwave coagulation therapy," Radiology., vol. 221, no. 1, pp. 167-172, Oct. 2001.

[10] A. S. Wright, L. A. Sampson, T. F. Warner, D. M. Mahvi, and F. T. Lee, "Radiofrequency versus microwave ablation in a hepatic Porcine Model," Radiology., vol. 236, pp. 132 -139, 2005

[11] T. J. Vogl, T. K. Helmberger, M. G. Mack, and M. F. Reiser (Eds.), "Ablative techniques (percutaneous) Th ermal Ablative Techniques," in Percutaneous Tumor Ablation in Medical Radiology, Berlin, Germany: Springer, 2008, pp. 7-32.

[12] S. Labonté, A. Blais, S. R. Legault, H. O. Ali, and L. Roy, "Monopole antennas for microwave catheter ablation," IEEE Trans. Microw. Theory Tech., vol. 44, no. 10, pp. 1832-1840, Oct. 1996.

[13] A. S. Wright, F. T. Lee, Jr., and D. M. Mahvi, "Hepatic microwave ablation with multiple antennae results in synergistically larger zones of coagulation necrosis," Annals of Surgical Oncology., vol. 10, no. 3 , pp. 275-283, 2003 .

[14] S. A. Shock, K. Meredith, T. F. Warner, L. A. Sampson, A. S. Wright, T. C. Winter III, D. M. Mahvi, J. P. Fine, and F. T. Lee, "Microwave ablation with loop antenna: in vivo porcine liver model," Radiology., vol. 231, no. 1, pp. 143-149, Apr. 2004.

[15] J. C. Lin, and Y.-J. Wang, "The cap-choke catheter antenna for microwave ablation treatment," IEEE Trans. Biomed. Eng., vol. 43, no. 6, pp. 657-660, Jun. 1996.

[16] D. Yang, J. M. Bertram, M. C. Converse, A. P. O’Rourke, J. G. Webster, S. C. Hagness, J. A. Will, and D. M. Mahvi, "A floating sleeve antenna yields localized hepatic microwave ablation," IEEE Trans. Biomed. Eng., vol. 53, no. 3, pp. 533-537, Mar. 2006.

[17] D. Panescu, J. G. Whayne, S. D. Fleischman, M. S. Mirotznik, D. K. Swanson, and J. G. Webster, "Three-dimensional finite element analysis of current density and temperature distributions during radio-frequency ablation," IEEE Trans. Biomed. Eng., vol. 42, no. 9, pp. 879-890, Sep. 1995.

[18] S. Tungjitkusolmun, E. J. Woo, H. Cao, J. Z. Tsai, V. R. Vorperian, and J. G. Webster, "Finite element analyses of uniform current density electrodes for radio-frequency cardiac ablation," IEEE Trans. Biomed. Eng., vol. 47, no. 1, pp. 32-40, Jan. 2000.

[19] E. J. Woo, S. Tungjitkusolmun, H. Cao, J. Z. Tsai, J. G. Webster, V. R. Vorperian, and J. A. Will, "A new catheter design using needle electrode for subendocardial RF ablation of ventricular muscles: Finite element analysis and in vitro experiments," IEEE Trans. Biomed. Eng., vol. 47, no. 1, pp. 23-31, Jan. 2000.

[20] E. J. Berjano, and F. Hornero, "Thermal-electrical modeling for epicardial atrial radiofrequency ablation," IEEE Trans. Biomed. Eng., vol. 51, no. 8, pp. 1348-1357, Aug. 2004

[21] D. Haemmerich, S. Tungjitkusolmun, S. T. Staelin, F. T. Lee, Jr., D. M. Mahvi, and J. G. Webster, "Finite-element analysis of hepatic multiple probe radio-frequency ablation," IEEE Trans. Biomed. Eng., vol. 49, no. 7, pp. 836-842, Jul. 2002.

[22] D. Haemmerich, S. T. Staelin, S. Tungjitkusolmun, F. T. Lee, D. M. Mahvi, and J. G. Webster, "Hepatic bipolar radio-frequency ablation between separated multiprong electrodes," IEEE Trans. Biomed. Eng., vol. 48, no. 10, pp. 1145-1152, Oct. 2001.

[23] K. M. Jones, J. A. Mechling, J. W. Strohbehn, and B. S. Trembly, "Theoretical and experimental $S A R$ distributions for interstitial dipole antenna arrays used in hyperthermia," IEEE Trans. Microwave Theory Tech., vol. 37, no. 8, pp. 1200-1209, Aug. 1989.

[24] S. Pisa, M. Cavagnaro, P. Bernardi, and J. C. Lin, "A 915-MHz antenna for microwave thermal ablation treatment: Physical design, computer modeling and experimental measurement," IEEE Trans. Biomed. Eng., vol. 48, no. 5, pp. 599-601, May. 2001.

[25] G. Schaller, J. Erb, R. Engelbrecht, and H. M. Seegenschmiedt, "Field simulation of applicators for interstitial microwave hyperthermia," IEEE MTT-S Digest., vol. 4, pp. 307-310, 1995.

[26] G. Schaller, J. Erb, and R. Engelbrecht, "Field simulation of dipole antennas for interstitial microwave hyperthermia," IEEE Trans. Microw. Theory Tech., vol. 44, no. 6, pp. 887-895, Jun. 1996.
[27] W. Hürter, F. Reinbold, and W. J. Lorenz, "A dipole antenna for interstitial microwave hyperthermia," IEEE Trans. Microw. Theory Tech., vol. 39, no. 6, pp. 1048-1054, Jun. 1991.

[28] J. C. Lin, S. Hirai, C.-L. Chiang, W.-L. Hsu, J.-L. Su, and Y.-J. Wang, "Computer simulation and experimental studies of SAR distributions of interstitial arrays of sleeved-slot microwave antennas for hyperthermia treatment of brain tumors," IEEE Trans. Microw. Theory Tech., vol. 48, no. 11, pp. 2191-2198, Nov. 2000.

[29] K. Saito, Y. Hayashi, H. Yoshimura, and K. Ito, "Heating characteristics of array applicator composed of two coaxial-slot antennas for microwave coagulation therapy," IEEE Trans. Microw. Theory Tech., vol. 48, no. 11, pp. 1800-1806, Nov. 2000.

[30] D. Yang, J. M. Bertram, M. C. Converse, A. P. O’Rourke, J. G. Webster, S. C. Hagness, J. A. Will, and D. M. Mahvi, "A floating sleeve antenna yields localized hepatic microwave ablation," IEEE Trans. Biomed. Eng., vol. 53, no. 3, pp. 533-537, Mar. 2006.

[31] Y. J. Lui, A. K. Qiao, Q. Nan, and X. Y. Yang, "Thermal characteristics of microwave ablation in the vicinity of an arterial bifution," Int. J. Hyperthermia, vol. 22, no. 6, pp. 491-506, Sep. 2006.

[32] P. Phasukkit, S. Tungjitkusolmun, M. Sangworasil, "Finite element analysis and in vitro experiments of placement configurations using triple antennas in microwave hepatic ablation", IEEE Trans. Biomed. Eng., vol. 56, no. 11, pp. 2564-2572, Nov. 2009.

[33] H. H. Pennes, "Analysis of tissue and arterial blood temperatures in the resting human forearm," J Appl Phy., vol. I, pp. 93-122, Aug. 1948.

[34] Tungjitkusolmun, S., Staelin, S. T., Haemmerich, D., Tsai, J.-Z., Cao, H., Vorperian, V. R., Lee, F. T. Jr., Mahvi D. M. and Webster, J. G., "Three-dimensional finite element analyses for radio-frequency hepatic tumor ablation", IEEE Trans. Biomed. Eng., vol. 49, pp. 3-9, Jan. 2002.

Wannaree Wongtrairat was born in Nakhonratchasima, Thailand, on March 19, 1979. She received the B.Eng. and M.Eng. degrees in telecommunications engineering in 2000 and 2003, respectively, and D.Eng. degree in Electrical Engineering in 2009 from King Mongkut's Institute of Technology Ladkrabang (KMITL), Bangkok, Thailand. She is a lecturer at the Department of Electronics Engineering, Faculty of Engineering and Architecture, Rajamangala University of Technology Isan, Nakhonratchasima. Her current research interests wireless communications and digital signal processing.

Pattarapong Phasukkit was born in Saraburi, Thailand, on May 18, 1978. $\mathrm{He}$ received the B.Eng. and M.Eng. degrees in telecommunications engineering in 2000 and 2003, respectively, and D.Eng. degree in Electrical Engineering in 2009 from King Mongkut's Institute of Technology Ladkrabang (KMITL), Bangkok, Thailand. He is a lecturer at the Department of Electronics Engineering, Faculty of Engineering, King Mongkut's Institute of Technology Ladkrabang, Bangkok. His current research interests include microwave ablation, antenna design, and wireless communications.

Supan Tungjitkusolmun was born in Bangkok, Thailand, December 5, 1972. He received the B.S.E.E. degree from the University of Pennsylvania, Philadelphia, in 1995, and the M.S.E.E. and Ph.D. degrees from the University of Wisconsin, Madison, in 1996, and 2000, respectively. He is an Assistant Professor at the Department of Electronics Engineering, Faculty of Engineering, King Mongkut's Institute of Technology Ladkrabang, Bangkok. From 2010 to 2011, he was the Associate Dean, Faculty of Engineering, King Mongkut's Institute of Technology Ladkrabang, Bangkok, Thailand. His research interests include finite-element modeling, radio-frequency ablation, microwave ablation, signal processing and image processing.

Petch Nantivatana was born in Bangkok, Thailand, on July 19, 1977. He received the B.Eng. degrees in Electrical Engineering in 2000 from Sripatum University, Bangkok, Thailand, M.Eng. degree in Electronics Engineering in 2006, from King Mongkut's Institute of Technology Ladkrabang (KMITL), Bangkok, Thailand. He is currently working toward the Ph.D. degree in electrical engineering. His current research interests include microwave ablation, signal and image processing and embedded system. 